\title{
GOAL, STRATEGIES AND PROGRAMME OF SAFE MOTHERHOOD IN NEPAL
}

\author{
Kamla Vashisth \\ School of Education, JNU, Jaipur, India
}

\author{
Om Prasad Baral \\ Department of Health Education \\ TU, Thakur Ram Multiple Campus, \\ Birganj, Nepal \\ email: ombaral@gmail.com
}

\begin{abstract}
The safe motherhood programme is one of the priority programme of Nepal. Its primary goal is to reduce maternal and neonatal mortality. Safe pregnancy, safe delivery and safe birth of new born are the major components of safe motherhood. This can be accomplished through increased access to effective antenatal, delivery and postnatal care and a massive health awareness activity in local communities.
\end{abstract}

\section{Keywords}

Ama programme; Antenatal care; Delivery; Postnatal care; Safe motherhood programme

\section{Introduction}

Safe motherhood means ensuring that all women receive the care they need to be safe and health throughout pregnancy delivery and postnatal period (Chitrakar, 2010). The aim of safe motherhood is to develop quality of maternal care and the reduce maternal mortality and neonatal mortality. Safe motherhood is the central component of all reproductive health related programmes. Safe motherhood further means creating of such a circumstance within which a woman is able to choose whether she desire to become pregnant or not. SM is matter of human right and social justice that is even crucial in those societies where there exists high gender gap between men and women. SM is great challenges for the entire world to make safe motherhood in reality. Different NGOs, INGOs ,and the government are also making enormous efforts to reduce maternal mortality and morbidity in Nepal. History of SM is not very long in Nepal. In 1950 family planning and maternal child health programme was started by a NGO. In 1987, WHO conducted an international conference in Nairobi, Kenya about safe motherhood, where all participating nations had agreed to implement safe motherhood programme in their countries (UN, 1996). In Nepal, in 1991, a steering committee had studied SM programme. On the basic of these studies in 1993, then GoN had decided implement SM programme. In 1998, MoH published the RH strategies, which included SM in integrated RH care package. This was 
followed by a SM policy document that related already contained in the plan of action 199497 and also gives very high priority to improve maternal and neonatal health status of the nation (FHD, 2001).

\subsection{Goal of safe motherhood and newborn health in nepal}

The goal of the national safe motherhood program is to reduce maternal and neonatal mortalities by addressing factors related to various morbidities, death and disability caused by complications of pregnancy and childbirth. Since its initiation in 1997, the safe Motherhood program has made significant progress in terms of the development of policies and protocols as well as expansion in the role of service providers such as staff nurses and ANMs in life saving skills. The policy on skilled birth attendants endorsed in 2006 by MoHP specially indentifies the importance of skilled birth attendance at every birth and embodies the government's commitment to training and deploying doctors and nurses/ ANMs with the required skills across the country.

In order to ensure focused and coordinated efforts among the various stakeholders involved in safe motherhood and neonatal health programming, government and nongovernment, national and international, the National Safe Motherhood Plan (2002-2017) has been revised with wide participation of partners. The revised Safe Motherhood National Health Long Term Plan (SMNHLTP, 2006-2017) includes recent development not adequately covered in the original plan. These include Recognition of the importance of addressing neonatal health as an integral part of safe motherhood programming: the policy for skilled birth attendants; health sector reform initiatives; legalization of abortion and the integration of safe abortion services under the safe motherhood umbrella, addressing the increasing problem of mother to child transmission of HIV/AIDS; and recognition of the importance of equity and access efforts to ensure that most needy women can access the services they need(DoHS,2010/11).

\subsection{Strategies of safe motherhood in nepal.}

Following strategies have been taken to achieve the goals of safe motherhood program as per related in $10^{\text {th }}$ plan.

a. Promoting inter-sectoral collaboration by insuring advocacy for and commitments to reproductive health, including safe motherhood at central, regional, district and community levels focusing on poor and excluded groups,

- Ensuring the commitment to SMNH initiative at all levels by promoting collaboration between sectors like health, education, and social welfare, legal and local development.

- Mobilizing national authorities, district health management committee, community leader and community member's to play active roles increasing suitable environment for promoting safe motherhood.

b. Strengthening and expanding delivery by skilled birth attendant, basic and comprehensive obstetric care service (including family planning) at all levels. Interventions include the following;

- Developing the infrastructure for delivery and emergency obstetric care.

- Standardizing basic maternity care and emergency obstetric care at appropriate levels of the health care system.

- Strengthening human resource management.

- Establishing functional referral system and advocating for emergency transport system and funds from communities to district hospitals for obstetric emergencies and high risk pregnancies.

- Strengthening community based 
awareness on birth preparedness and complication readiness through FCHVs increasing access of all relevant maternal health information and service.

c. Supporting activities that raise the status of women in society.

d. Promoting research on safe motherhood to contribute to improved planning higher quality services, and more cost effective interventions.

\subsection{Major activities of safe motherhood in Nepal}

Nepal government, MoHP has been implementing safe motherhood program all over the country on the basis of following activities;

\section{a. Birth preparedness package and mnh activities at community level}

Family Health Division (FHD) continued support for expansion and maintenance of MNH actives at community level which includes revised Birth Preparedness Package (Jeevan suraksha Flip chart and Jeevan Suraksha Card) and Matri Suraksha Chakhi (Misoprostol) distribution for prevention of post partum Haemarrhage (PPH) at home delivery focusing continuum of care from pregnancy, through birth and post partum period, including the newborn. Such community level activities promote strengthening birth preparedness and complication, readiness (Preparedness of money, SBA/ health facilities, transport and blood donors), promotion of ANC/PNC service (Iron, T.T, Albendazole), Self-care in pregnancy and post partum period (Food, rest, no smoking and no drinking alcohol), identification and prompt care seeking for danger signs in pregnancy, delivery and postpartum period and education and distribution of Matri Suraksha chakki for prevention of $\mathrm{PPH}$ at home delivery.

These community level interventions have increased the demand and access of information and service at the community level. This has contributed to increase the service utilization in pregnancy, delivery and post partum care including essential new born care.

\section{b. Rural ultrasound programme}

The objective of this program is to identify the complication during pregnancy referral to the appropriate health faculty for complication, management. This program is being piloted in two District Mugu and Dhading. The preliminary finding shows the increment in ANC cases and increased timely referral to higher centers. In this program attained nurse use a portable ultrasound machine for scan purpose only.

\section{c. Uterine prolapsed}

Uterine prolapsed (UP) relates nearly every aspect of mandate in the area of RH and Rights gender equity, and empowerment of women. The main factors that directly and indirectly cause this morbidity have the potential to serve as an entry point for improving women's $\mathrm{RH}$ and reproductive rights. While up is not an MDG indicator, it is indirectly related to goal.

Uterine prolapsed is the priority one program of GoN. In the last four years separate fund has been allocated for uterine prolapsed. Uterine prolapsed treatment and surgery operational guideline 2008, first revision 2009 has been development and one focal person has been identified in the FHD.

\section{d. Human resource}

FHD has been coordinating with NHTC provide SBA training to doctors and staff nurses. Since in-service SBA training was initiated in 2007.

\section{e. Emergency referral fund}

It is very important to have referral services to the pregnant woman in the remote districts. To address this issue FHD has launched 
emergency referral fund program to facilitate referral services in 14 districts namely Bhojpur, Khotang, Sunsari, Rasuwa, Manag, Mustang, Dolpa, Humla, Jajarkot, Mugu, Rolpa, Rukum, Bajang and Darchula. A total of two hundred thousand rupees has been allocated as seed money for each district to be used by a locally formed committee as per the guidelines. The main objectives of this program into provide the referral services to women from poor, Dalit, Janapati, geographically disadvantages, socially and economically disadvantage communities who need caesarean section (ClS) or complication management during pregnancy.

\section{f. Safe abortion services}

Preventing unwanted pregnancies through a quality family planning services is a first step towards addressing women's reproductive health needs, and increasing access to safe abortion service has been considered as a missed opportunity to prevent unwanted pregnancy however, there is a dearth need to make this service available in order to prevent mortality and morbidity from unsafe abortion. A comprehensive approach needs to be integrated between three services; family planning, safe abortion and post abortion care. This means ensuring the availability of comprehensive abortion and post abortion care. This means ensuring the availability of comprehensive abortion care (CAC) that refers termination of unwanted pregnancies through safe technique with effective pain management, post procedure family planning information and service to ensure women are able to plan when to have children and avoid further unwanted pregnancies. Only trained doctors or health worker can provide safe abortion services at the government approved health facilities, with the consent of women and according to the national's standard.

\section{g. Aama programem}

Aama program has four components: i) the safe delivery incentive program (SDIP), a cash incentive scheme, which was initiated in
July 2005, 2) Free institutional delivery care, which was launched in mid-January 2009, 3) incentive to health worker for home delivery and 4 ) inceptive to women for four ANC visits. The Aama program has following provisions and it has been practically implemented in the communities.

- Incentives to women on institutional delivery. A cash payment is made to women immediately following institutional delivery: NRS 1,500 in mountain, NRS 1000 in hill and NRs. 500 in terai region.

- Free institutional delivery services : A payment to the health facility for the provision of free delivery care: For a normal delivery service health facilities with less than 25 beds receive NRs 1000; health facilities with 25 or more beds receive NRs 1,500.For complicated deliveries health facilities receive NRs 3000, for each C/S NRs 7,000.

- Incentive to women for four ANC visits: A cash payment of NRs 400 is made to women on completion of four ANC visits at the 4,6,8 and 9 months of pregnancy following institutional delivery.

- Incentives to health worker for home deliveries: A cash payment of NRs 100 is made to health worker for home deliveries. Copies of birth registration or death certificate need to be produced to claim incentives for home deliveries (DoHS, 2011/12).

\subsection{Situation of safe motherhood in Nepal}

While 83percent of all mothers received antenatal care services less than three fifths had four antenatal care checkups indicating that more than two fifths of mother did not complete the recommended four check-ups. There was a large increase in skilled birth attendance at deliveries from 32percent in 2009/o10 to 44percent in 2011/012. There was also a large increase in institutional deliveries from 31percent of all deliveries in 2009/010 to 
44 percent in 2011/o12. Post-natal care check -ups 51percent in 2011/012. More than twofifths of pregnant women (43.3\%) benefited from free institutional delivery care under the Aama program and 43percent received its transport incentive in 2011/012(DoHS, 2012).

\section{Conclusion}

In Nepal, majority of inhabitants are facing SM health related complications and treating with the causes of material and child death. Most of the women in poverty shaded are as die because of three delays such as in seeking care, in reaching care and receiving care. These causes are occurring due to ignorance, male dominated society, gender discrimination, repeated pregnancies, limited availability of health service and no use of health service, deeply rooted superstition and different cultural attitudes etc. This requires extended programmes to improve the quality of SM service with greater participation of the community.

\section{References}

Chitrakar,G.(2010).Family health and reproductive health. Kathmandu: Makalu Publication.

DoHS (2010/11). Annual Report. Government of Nepal. Kathmandu : DoHS.

DoHS (2011/12). Annual Report. Government of Nepal. Kathmandu : DoHS.

DoHS (2012). Annual Report. Government of Nepal. Kathmandu : DoHS.

FHD(2001). Safe motherhood news letter. Maternal situation in Nepal 2-3.

UN (1996). Programme of action: International conference on population and development (ICPD) New York : UNFPA. 